\title{
An empirical analysis of students' learning and achievements: A motivational approach
}

\author{
Huy P. Phan, Bing H. Ngu \\ School of Education, the University of New England, Armidale NSW 2351, AUSTRALIA \\ Email address: \\ hphan2@une.edu.au (H. P. Phan), bngu@une.edu.au (B. H. Ngu)
}

To cite this article:

Huy P. Phan, Bing H. Ngu. An Empirical Analysis of Students' Learning and Achievements: A Motivational Approach. Educational Journal. Vol. 3, No. 4, 2014, pp. 203-216. doi: 10.11648/j.edu.20140304.11

\begin{abstract}
The present study details a theoretical-conceptual model, scoping the interrelations between antecedents (academic buoyancy, emotional and physiological states, task value), cognitive processes (habitual action, critical reflection), and adaptive outcomes (academic engagement, academic achievement) in the context of educational psychology. 294 (151 men, 143 women) first-year university students participated in this study. Likert-scale inventories were administered to students and used to elicit relevant data; for example, we used the Academic Buoyancy Scale $[1,2]$, and the Task value subscale of the Motivated Strategies for Learning Questionnaire (MSLQ)[3]. Academic achievement was collated from students' overall marks in the unit educational psychology. Structural equation modeling (SEM) analyses supported, in part, the conceptual model with some statistical significant paths. In general, on the basis of the findings yielded, there are significant implications for research development and educational practices.
\end{abstract}

Keywords: Antecedents, Cognitive Processes, Achievement Outcome

\section{Introduction}

Quality learning, entailing interest, improvement of skills, and mastery, is an important component for recognition. Academic learning, in this sense, emphasizes other related attributes, such as intellectual curiosity, personal best, and the inner desire for gratification. Educators and researchers often seek to explore theoretical orientations and psychosocial factors that explain proactive engagement and individuals' academic successes [e.g., 4, 5-8]. Cognitive (e.g., processing strategies) and motivation (e.g., intrinsic motive) tenets, for example, may account why some individuals achieve and surpass others in educational contexts [9]. This inquiry into the impact of quality learning, from our point of view, is advantageous as it focuses on non-deficit, positive reasoning - for example, how can we assist and enhance students' engagement?

The present study, consequently, seeks to explore a number of theoretical orientations that could account for university students' learning in achievement contexts. A synthesis of the literature indicates there are a number of constructs that contribute to the prediction and enhancement of adaptive outcomes and positive behaviors. Our main research objective, in particular, entails the optimization of students' learning and performance outcomes via cognitive and motivation processes. The theoretical-conceptual model that we have articulated, similar to some recent studies [e.g., 4, 5, 6, 10], is significant for its amalgamation of three major, sequential processes: (i) antecedents (academic buoyancy, emotional and physiological states, and task values), (ii) cognitive processes (habitual action and critical reflection), and (iii) adaptive outcomes (engagement and academic achievement). This conceptualization unifies inquiries pertaining to relations between academic achievement and non-cognitive processes of learning (e.g., task value)[1, 10, 11], and the relations between cognitive processes and adaptive outcomes (e.g., achievement)[12, 13]. To our knowledge, very few research studies have yet unified the two mentioned research strands within one study. Such unification, in our view, may shed important insight into the trajectories amongst the various theoretical frameworks of learning.

The theoretical-conceptual model proposed for this investigation details the intricacy of both cognitive and non-cognitive process outcomes in achievement contexts. The hypothesized structural relations, as depicted in Figure 1 , illustrate the predictive and explanatory effects of academic buoyancy, emotional and physiological states, and task values on academic engagement and achievement, 
via habitual action and critical reflection. There is empirical evidence, which we examine in the subsequent sections, to support the sequential ordering in associations between the variables. Findings obtained from the present study may provide a basis for discussion and continuing research development, cross-culturally, into students' processes of effective learning. One notable avenue of inquiry, for example, entails the potential to situate our hypothesized model in other sociocultural contexts.

\subsection{Academic Buoyancy, Emotional and Physiological States, and Task Values}

Research into student learning, encompassing both cognitive and motivational theories, has involved conceptualizations [e.g., 4, 5, 6, 10] that depict intricate interrelationships, whereby a number of constructs serve as antecedents of adaptive outcomes. Our examination of the empirical literature indicates some notable psychosocial factors and motivational processes that could serve as potent antecedents. In the context of the present investigation, we choose to explore three main theoretical constructs: academic buoyancy, task values, and emotional and physiological states. This emphasis, from our point of view, is significant, given very few, if any, studies have investigated these antecedents, in totality, within one theoretical-conceptual framework.

Martin and Marsh (2008a) defined as academic buoyancy as "an individual's capacity to successfully overcome setbacks and challenges that are typical of the ordinary course of everyday" (e.g., poor performance, competing deadlines, performance pressure, difficult tasks: Martin \& Marsh, 2008a)[2]. The theoretical grounding of academic buoyancy is based on the belief that resilience, a construct that is similar in nature and characteristics, has limited applicability and does not cater for the challenges and adversities that are typical of daily academic life [14]. There is evidence, albeit limited at present, to suggest that academic buoyancy influences both educational (e.g., enjoyment of school, class participation) and psychological (e.g., general self-esteem, self-efficacy) outcome measures $[6,15]$. Martin and Marsh's (2008a) longitudinal study, for example, has yielded some preliminary findings to show the predictive and explanatory powers of academic buoyancy in educational settings (e.g., Time 1 academic buoyancy influenced Time 2 anxiety $(\beta=-.10, p<.01)$ ). Martin and Marsh's (2006) previous work, likewise, reported the predictive effects of academic buoyancy on general self-esteem $(\beta=.51, p<.05)$, class participation $(\beta$ $=.32, p<.05)$, and enjoyment of school $(\beta=.32, p<.05)$.

The inclusion of academic buoyancy as an antecedent is sound, given its characteristics and the fact that existing empirical findings have attested to its potency $[1,2,6]$. Structural validity established in the present study would provide empirical evidence, supporting previous research investigations regarding the characteristics and impact of academic buoyancy. In a similar manner, we proposed the inclusion of task values, grounded within the expectancy-value theoretical framework [11, 16], as an antecedent. Eccles and her colleagues identified several types of subject task values, notably: attainment value or importance, intrinsic value, and utility value or usefulness of the task [see 16 for detail]. There is extensive research [e.g., 10, 17-20] that shows the positive contributions of the various types of task values on learning and achievement-related outcomes and behaviors. A learning task that has utility values, say, may assist students beyond the immediate situation of a classroom. Tasks with intrinsic values, likewise, are interesting and may stimulate appreciation and intellectual curiosities, mediating students' social interactions, proactively in classroom and non-classroom settings [17].

The predictiveness of task values, as stipulated by the expectancy-value theoretical framework $[11,16]$ and previous research findings, indicates the potential of this construct as a predictor of achievement-related outcomes. We query, for instance, the plausibility that task values could contribute to the prediction of cognitive processes. The valuing of a learning task or activity (e.g., how to filter rainwater) for its perceived usefulness or importance may result in students adopting a favorable mindset, facilitating them to approach learning with a view to improve and develop personal competence. Consequently, arising from this personal attention and approach to learning, students may actively seek out critical reflective skills for assistance. This proposition is consonant with existing research studies, which have reported the positive associations between task value and various cognitive-motivational constructs: achievement goal types [e.g., 10, 12, 18, 21], choice behaviors, persistence, and effort [16, 22]. Similarly, in relation to learning approaches, Liem, et al. (2008) found that task value influenced both deep $(\beta=.22, p<.05)$ and surface $(\beta=.37, p<.05)$ learning approaches indirectly, via mastery goals. Subjective task value, especially in terms of intrinsic values [e.g., "I am very interested in the content area of this subject": 23] may espouse and relate to intrinsic motivation. Students who inquire and learn a subject matter because of its intrinsic value (e.g., learning how to filter rainwater) may, in this analysis, partake and engage in related exercises and activities for their own sake. What this means then is that subjective task value may feature as an important determinant of positive behaviors and adaptive outcomes.

Emotional and physiological states, according to social cognitive theory [24, 25], may operate as an important source of information in the cognitive appraisal of capabilities. Affective responses, such as anxiety, apprehension, and mood swing are indicative of one's own resolute, capableness, and vulnerability to deal with dysfunctions and educational-related tasks, situations, and events (e.g., a student's high state of anxiety before a final exam in mathematics). Negative affective responses such as anxiety, similarly, tend to weaken academic achievement and have been shown to relate inversely with self-beliefs 
for learning (e.g., personal self-efficacy)[25-27].

Given their characteristics, we expect to find emotional and physiological states to relate inversely with critical reflection. Students who demonstrate positive affect (e.g., happiness) and are well-versed, academically, would feel more buoyant and confident to partake in learning activities and confront challenges with an open mindset. It is also expected that this informational source would associate positively with habitual action. Students who are inefficacious and exhibit negative affective responses (e.g., exam anxiety) would tend to expend minimal effort, avoid working (e.g., adopting work-avoidance goals), and gravitate towards strategies (e.g., seeking help) that support habitual action.

\subsection{Internal Cognitive Processes}

The intricacy of academic learning also involved the operational nature of internal cognitive processes, which could act in tandem with other psychosocial factors and/or motivational constructs to influence adaptive outcomes. A theoretical review indicates there are a number of cognitive processes that account for students' learning in achievement contexts, for example: effort expenditure, persistence, and study processing strategies. We choose, in this case, to explore two contrasting processing strategies: habitual action versus critical reflection. These two dichotomous constructs, based on Kember, et al.'s work [13, 28], are grounded, theoretically, within the framework of reflective thinking [29-31]. This analysis connotes that individuals, in their quest to learn and master a subject matter, would adopt and exhibit a myriad of cognitive skills relating to reflective thinking. Habitual action is more simplistic, whereby learning is automated and very little conscious thought is involved (e.g., solving arithmetic mathematics problems that involve addition and subtraction). In this sense, according to Kember, et al. (2000), habitual action indicates very little, if any, reflection in the learning process Critical reflection, in contrast, is more complex and entails a cognitive transformation in one's ability to critique presuppositions and prior learning. Development of critical reflection skills, in particular, enables individuals to make complex hypotheses for further investigation and addressing.

Both habitual action and critical reflection, according to Kember, et al. [13, 28], are opposite in scope and characteristics, resulting in differing patterns in relationships with other cognitive-motivational variables. Relationships between habitual action and critical reflection and other variables, however, have been limited in terms of empirical validation. Within the past decade, for example, very few research studies have explored habitual action and critical reflection and their impacts in educational contexts. Apart from Kember, et al.'s (2000) original study, which focused on the psychometric properties of the Reflective Thinking Questionnaire (RTQ), the works of Phan (2007, 2009) and Leung and Kember (2003) have been relatively prominent.
Characteristics of habitual action and critical reflection, and construct validity of the RTQ [28], have been verified with Leung and Kember's (2003) study. Confirmatory factor analysis (CFA), reported by the authors, indicated that habitual action was more closely associated with a surface approach to learning ( $\alpha=.65, p<.05)$, whereas critical reflection was associated with a deep approach to learning $(\alpha=.50, p<.05)$. Phan's $(2007,2009)$ research involving university students also produced some interesting patterns in findings, for example: the negative impact of personal self-efficacy [25] on habitual action ( $\beta=$ $-.31, p<.05)$, and the positive impact of a deep learning approach on critical reflection $(\beta=.26, p<.05)$.

The important question then, for consideration, is whether and to what extent both habitual action and critical reflection could feature as central processes in student learning. Similarly, in terms of advancing our understanding of the characteristics of these two cognitive constructs, it would make logical sense to consider their potential associations with academic buoyancy, emotional and physiological states, and task values. This aspect of the present research inquiry is exploratory in nature, given there is limited research, at present that has delved into the antecedents of habitual action and critical reflection [32, 33]. Does academic buoyancy, as a form of motivation, associate positively with critical reflection, and negatively with habitual action? Is anxiety indicative of one's inclination to practice habitual learning?

\subsection{The Emphasis on Academic Engagement and Achievement Outcome}

Situating both habitual action and critical reflection as central constructs in the learning process is significant, theoretically, and may provide fruitful information regarding educational practices for implementation. The quest then, similarly, is for us to explore the potential impacts of habitual action and critical reflection on adaptive outcomes. From a positive, non-deficit perspective, it is important to identify contributors and enhancers of proactive engagement and academic learning in achievement contexts. Stipulating academic engagement as an adaptive outcome, from our point of view, is integral to our understanding of the interrelations between the three antecedents and two internal cognitive processes - for example, the impact of academic buoyancy on critical reflection, which in turn influences academic engagement and achievement outcome.

Academic engagement is an important theoretical facet, which has to date been explored extensively by a number of educators and researchers [34-38]. In its simplistic term, according to Axelson and Flick (2010), academic engagement or student engagement is defined as to 'how involved or interested students appear to be in their learning and how connected they are to their classes, their institutions, and each other' [39] and as 'the degree to which students are 'connected' to what is going on in their classes' [40]. This schooling construct has been noted to 
make a major contribution in the prediction of students' motivation and quality learning in achievement contexts $[37,38,41-43]$.

Indeed, from an educational perspective, Kuh's (2009) theoretical overview indicates the significance of engagement and how this construct has spanned the course of seven decades. Over the past 70 years, for example, the engagement premise has evolved to include different definitions and meanings - the importance of quality of effort [44], student involvement [45], social and academic integration [46, 47], good practices in undergraduate education [48], etc. Engagement, since then, entails student engagement $[49,50]$ and encompasses attributes, such as quality of effort and involvement in productive learning activities [51]. Furthermore, in accordance with this progress, the development of the National Survey of Student Engagement (NSSE) and the Community College Survey of Student Engagement (CCSSE)[52-54] has provided information regarding the measure of student engagement, and how this construct serves as an indicator of learning, personal development, and institutional performance [35, 51].The College Student Report, in the NSSE, asks students to report the frequency with which they partake in activities that reflect good educational practice (e.g., utilizing institution's human resources; curricular programs; the amount of reading and writing students did during the year; the number of hours per week one devotes to schoolwork, etc.).

From a motivational perspective, similarly, we contend that academic engagement also encompasses a number of attributes, such as personal interest and curiosity for learning, attention, and class attendance. These attributes operate in tandem with other cognitive-motivational constructs (e.g., deep cognitive strategies) to stimulate students' learning and academic performance [14, 38]. The work of Schaufeli, Salanova, González-Romá, and Bakker, (2002), for example, is notable, emphasizing cognitive-motivational facets, including: (i) absorption, which is characterized by one's own engrossment in a learning task, (ii) dedication signifies a sense of enthusiasm, inspiration, pride, and challenge, and (iii) vigor emphasizes an individual's willingness to invest effort in learning, and his/her mental resilience while working and persistence in the face of obstacles [55]. The Engagement Scale, developed by Schaufeli, et al. (2002), has three subscales, corresponding to vigor ( 9 items), dedication ( 8 items), and absorption ( 7 items).

There is an emerging interest from researchers to accept engagement as a multifaceted construct [43, 54, 55]. Schaufeli, et al.'s (2002) theoretical tenets have, however, received modest attention in terms of examination and empirical validation. We believe there is credence, though, to lend support for Schaufeli, et al.'s (2002) conceptualization, given the mentioned attributes (e.g., absorption) reflect a motivational approach to our understanding of students' engagement in academia. This emphasis, we believe, may extend Kuh's previous research
$[49,50,54]$ and provide an alternative account to students' engagement.

In relation to the inclusion of academic engagement then, the question for consideration is whether and to what extent both superficial and deep cognitive processes could relate and explain students' engagement towards schooling. Existing theoretical tenets $[13,28]$ seem to indicate that, for instance, habitual action and superficial would reflect a work-avoidance mindset, whereby students are more inclined to disengage and exhibit a number of maladaptive-related attributes. We contend that deep cognitive processes, in contrast, would facilitate proactive behaviors, such as students manifesting more engagement in schooling, consequently as a result of other cognitive-motivational processes. It is plausible to suggest that affective responses, in conjunction with effort expenditure, could associate with critical reflection to motivate and engage students (e.g., critical reflection mobilizes a student to expend more effort in his/her learning, consequently, resulting in engagement.

There is some evidence to indicate that both habitual action and critical reflection exert varying effects on achievement-related outcomes. The work of Phan (2009), for example, has provided empirical support, highlighting the positive predictive effect of critical reflection on both quality learning $(\beta=.70, p<.05)$ and achievement outcome $(\beta=.57, p<.05)$. Leung and Kember's (2003) study, similarly, yielded a pattern in findings, emphasizing the potency of critical reflection and its association with a deep approach to learning. Habitual action, in contrast, given its nature and characteristics [e.g., automated action with minimal effort and conscious thought: 28] is expected to result in maladaptive practices. We anticipate that this type of superficial cognitive processing would compel many individuals to manifest 'anti-academic' behaviors, such as work-avoidance and academic disengagement, in general, towards schooling.

Given prior research findings, we contend that both academic buoyancy and task values could also influence students' academic engagement, given their attested predictive effects on achievement-related outcomes $[1,14$, 16]. The valuing of an academic task, based on a perception of utility or interest (e.g., I find this topic on Algebra very interesting as it seems to relate to what I want to do), may compel students to approach learning with a sense of keenness, deliberation, and motivation, thereby embedding themselves more proactively in schooling, etc. Buoyancy, in a similar vein, reflects a sense of resilience, motivating students to persist in the face of setbacks and obstacles.

Emotional and physiological states, according to Bandura (1986, 1997), associate inversely with personal self-efficacy and other-related processes. A heightened state of anxiety, for example, is related to one's inefficacy beliefs for learning and self-regulation. This line of evidence, as shown in the work of Pajares and colleagues [56-58], is significant, theoretically, and may extend to the outcome of academic engagement and disengagement. Students who 
have a high state of anxiety and/or exhibit other affective responses would more likely feel disengaged from classroom learning and schooling, altogether. These students would, similarly, align and demonstrate other negative-related attributes, such as an orientation towards work-avoidance goals.

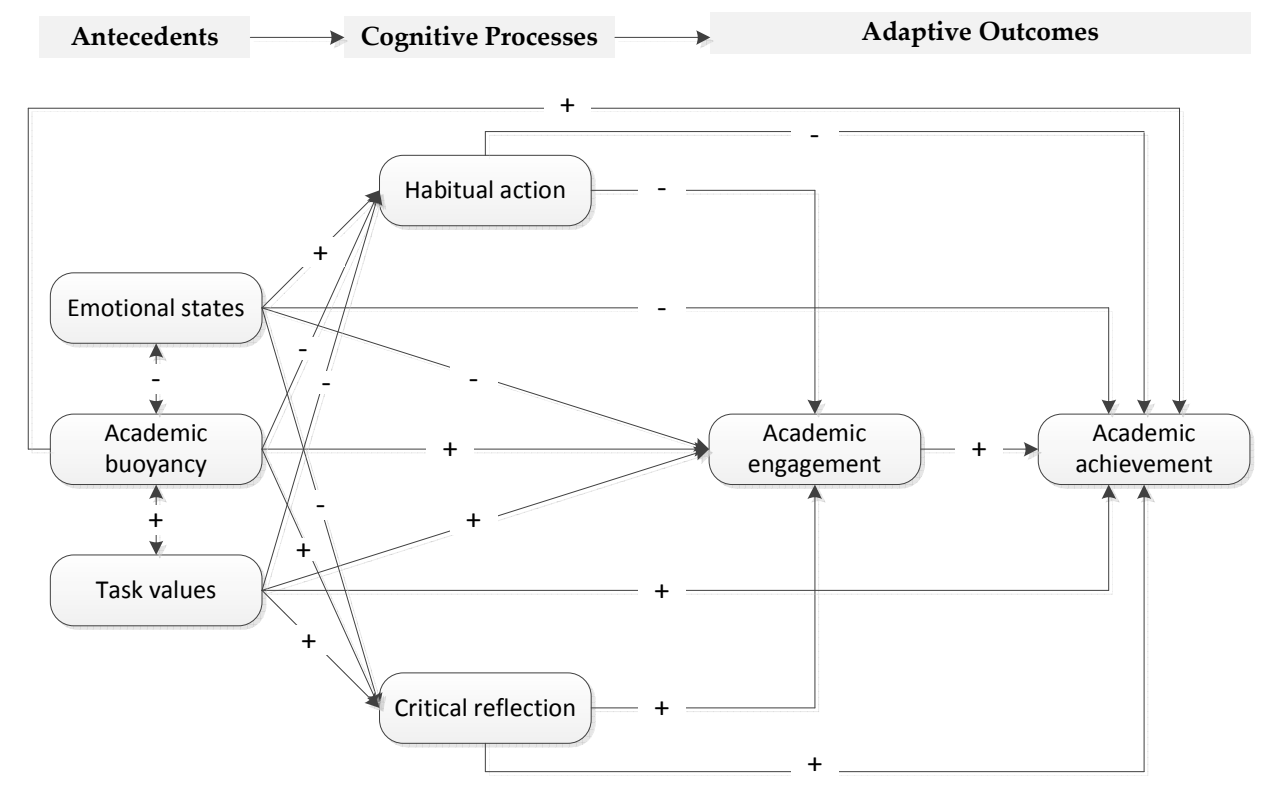

Figure 1. A Conceptual Model of Cognitive-Motivational Processes for Learning.

\subsection{In Totality: The Impact on Academic Achievement}

The study of quality learning in achievement contexts, overall, entails the inclusion of a number of psychosocial factors and cognitive-motivational constructs for empirical examination. The theoretical-conceptual framework that we formulate reflects the complexity in interrelationships between constructs that could account and explain students' achievements. The preceding sections illustrate an important scope in associations, detailing the possible contributions of three major antecedents: emotional and physiological states, academic buoyancy, and task values. We amalgamated different theoretical orientations [e.g., expectancy-value theory: 11, 16] and strands of research inquiries within the one study for investigation, stipulating in this case four major hypotheses:

HP1: Emotional and physiological states will exert negative effects on critical reflection, academic engagement and achievement, and a positive effect on habitual action.

HP2: Both academic buoyancy and task value will exert positive effects on critical reflection, academic engagement, and achievement, and negative effects on habitual action.

HP3: Habitual action will exert negative effects on academic engagement and achievement, whereas critical reflection will exert positive effects on these two variables.

HP4: Academic engagement will relate positively with achievement.

Overall, the proposed hypotheses for examination have a number of theoretical and practical merits for consideration.
Empirical evidence established may provide a basis for continuing conceptualization and research development within the sociocultural contexts of the Asia-Pacific region. Notably, one potential aspect for discussion entails the cross-cultural generalizability of the present theoretical-conceptual model to other Asian countries. How does academic buoyancy make a contribution towards the prediction and enhancement of quality learning of Non-Western students?

\section{Method}

\subsection{Participants}

Participants in the present study were 294 (151 men, 143 women) first-year university students enrolled in Teacher Education courses at a university in Australia. The ages of the students ranged from $18-44(M n=24.5, S D=1.76)$. Participation by the students was voluntary and no remuneration was provided. Students were also instructed to write down their names for the main purpose of identification in terms of their end-of-semester results. Students were assured of anonymity and that their responses would only be seen by the researchers involved in the study. Finally, in relation to answering the questionnaires, we asked the students to situate their responses within the context of the subject Educational Psychology, as they were enrolled in this unit at the time.

\subsection{Instruments}

Academic Buoyancy. We used four items from the Buoyancy Scale [1, 2, 15] to measure academic buoyancy. 
The sample items, self-rated on a 7-point scale (1 (Strongly disagree) to 7 (Strongly agree)), included, for example:
"I'm good at dealing with setbacks" and "I don't let study stress get on top of me".

Table 1. Descriptive Statistics of Means and Standard Deviations.

\begin{tabular}{|c|c|c|c|c|}
\hline Instruments & Means & & Means & Cronbach \\
\hline & $\operatorname{Men}(N=151)$ & Women $(N=143)$ & $\begin{array}{l}\text { Total sample }(N= \\
294)\end{array}$ & \\
\hline Academic buoyancy & $4.485(1.475)$ & $4.550(1.457)$ & $4.516(1.464)$ & .94 \\
\hline Emotional and Physiological States & $2.201(1.121)$ & $2.219(1.115)$ & $2.210(1.117)$ & .85 \\
\hline Task values & $5.713(1.028)$ & $5.727(1.004)$ & $5.720(1.015)$ & .91 \\
\hline Habitual action & $2.219(1.051)$ & $2.226(1.024)$ & $2.222(1.036)$ & .84 \\
\hline Critical reflection & $5.400(.755)$ & $5.395(.762)$ & $5.397(.757)$ & .65 \\
\hline Academic engagement & $5.750(.888)$ & $5.808(.839)$ & $5.778(.863)$ & .88 \\
\hline
\end{tabular}

Note: Standard deviations are shown in brackets.

Academic Engagement. There are a number of inventories, which measure and assess students' academic engagement $[54,55,59,60]$. Given the focus of the present investigation is grounded in a cognitive-motivational approach, we chose to use Schaufeli, et al.'s (2002) Engagement Scales, Student Version, to measure university students' academic engagement. The three subscales, as detailed previously, contain self-report items that emphasize and reflect motivation-related attributes, such as learning engrossment, enthusiasm, resilience, and effort expenditure. The Engagement Scales, overall, have been found to demonstrate good construct validity, relevance, and applicability to classroom learning $[55,61]$. The 17 items, answered on a 7-point rating scale (1 (Strongly disagree) to 7 (Strongly agree)), defined three distinct dimensions of engagement: Vigor (e.g., "When I get up in the morning, I feel like going to [lectures] and [tutorial] classes"), Dedication (e.g., "To me, my studies [at university] are challenging"), and Absorption (e.g., "When I am studying, I forget everything around me"). We also modified the wordings of some items to suit university learning contexts. This revision has been validated in our previous research, which has been published recently [61].

Emotional and Physiological States. We adapted the emotional and physiological states subscale of previous inventories $[62,63]$ to measure students' emotional and physiological states. The six items, rated on a 7-point rating scale (1 (Definitely disagree) to 7 (Definitely agree)), included, for example: "This subject, educational psychology, makes me stressed and nervous" (Emotional and physiological states).

Habitual Action and Critical Reflection. Both cognitive processing types were measured using Kember, et al.'s (2000) Reflective Thinking Questionnaire (RTQ). The RTQ contains 16 items, defining four major subscales: Habitual Action, Understanding, Reflection, and Critical Reflection. For this study, we used the Habitual Action and Critical Reflection subscales, with each subscale containing four items rated on 7-point rating scale (1 (strong disagree) to 7 (strongly agree)). The sample items included, for example: "When I am working on some activities, I can do them without thinking about what I am doing" (Habitual Action) and "As a result of this unit, educational psychology, I have changed the way I look at myself' (Critical Reflection).

Task Values. We used the task value subscale of the Motivated Strategies for Learning Questionnaire (MLSQ)[23] to measure task values. The subscale, containing six items measured on a 7-point rating scale (Strongly disagree) to 7 (Strongly agree)), describes values pertaining to interest (e.g., "I am very interested in the content area of this subject, educational psychology"), perceived usefulness (e.g., "I think I will be able to use what I learn in this subject, educational psychology, in other subjects"), and importance (e.g., "It is important for me to learn the subject material in this class").

Academic Achievement. Academic achievement was measured by collating students' unit mark at the end of the semester. The unit that the students enrolled does not have a formal final exam, but rather entailed continuous assessment tasks (e.g., Reading response task). There is, however, an end-of-semester quiz (20\%), which consists of multiple-choice, true/false, and matching questions for answering.

\section{Results}

We used structural equation modeling (SEM) [64-66] to test the hypothesized a priori model described. This statistical technique emphasizes the importance of both latent factors and measured indicators, whereby the latter is assumed to have true errors (i.e., $\mathrm{E} \neq 0$ ). Unlike other multivariate statistical techniques, SEM enables researchers to test and compare competing a priori models.

The statistical software packages SPSS21 and SPSS AMOS 20 were used to assist in the descriptive and latent variables analyses. Following the protocols that have been established previously [64, 65, 67], we used covariance matrices and maximum likelihood solutions. Maximum likelihood procedure, similarly, has been noted to perform reasonably well when data are normally distributed [68]. In relation to the goodness-of-fit index values, we chose to use the following: (i) the chi-square statistics $\left(\chi^{2}\right)$ and degree of freedom (df), (ii) Comparative Fit Index (CFI)(CFI $\geq .90$ ), (iii) the Non-normed Fit Index (NNFI)(NNFI $\geq .90$ ), and (iv) the Root Mean Square Error of Approximation (RMSEA)(RMSEA $\leq .080)$. Finally, Cronbach's alpha 
values and descriptive statistics, involving the means and standard deviations for the total sample and individual groups (men versus women) are presented in Table 1. Table
2, similarly, presents the correlations among variables involved in the model for statistical testing.

Table 2. Correlations between Variables

\begin{tabular}{|c|c|c|c|c|c|c|c|c|c|c|c|c|c|}
\hline Variables & 1 & & 2 & & 3 & & 4 & & 5 & & 6 & & 7 \\
\hline 1. Academic buoyancy & 1.00 & & & & & & & & & & & & \\
\hline Emotional states & .041 & & 1.00 & & & & & & & & & & \\
\hline Task values & .116 & $*$ & .016 & & 1.00 & & & & & & & & \\
\hline Habitual action & .163 & $* *$ & .434 & $* *$ & -.049 & & 1.00 & & & & & & \\
\hline Critical reflection & -.004 & & -.001 & & .078 & & .053 & & 1.00 & & & & \\
\hline Academic engagement & -.055 & & .133 & * & .266 & $* *$ & .136 & * & .034 & & 1.00 & & \\
\hline 7. Academic achievement & .068 & & -.016 & & .152 & ** & .106 & & .158 & $* *$ & .463 & $* *$ & 1.00 \\
\hline
\end{tabular}

Note: $* p<.05, * * p<.01$

\subsection{Structural Relations between the Variables}

We tested a number of a priori models that reflected the hypotheses mentioned previously. Specifically, in relation to Figure 1, we focused on two major types of structural paths - paths that originated from emotional and physiological states, academic buoyancy, and task values to habitual action and critical reflection, and paths that originated from habitual action and critical reflection to academic engagement and achievement outcome. The first model we tested, Model $\mathrm{M}_{1}$, denoted the hypothesized model with the exception of the following structural paths, which we did not include: (i) habitual action to academic engagement and achievement, critical reflection to academic engagement and achievement, (ii) task value to habitual action, and (iii) academic buoyancy to habitual action. The initial test showed that the data fitted the hypothesized model relatively well: $\chi 2 / \mathrm{d} f=3.215$, $\mathrm{p}$ $<.001, \mathrm{CFI}=.905$, RMSEA $=.087$.

Continuing on with the initial model, we progressively included structural paths for statistical testing in order to ascertain an appropriate model fit. We extended Model $\mathrm{M}_{1}$, which included the possible negative effects of habitual action on academic engagement and achievement, and the possible positive effects of critical reflection on these two adaptive outcomes. Including these four structural paths yielded an improvement in model fit for this model, Model $\mathrm{M}_{2}: \chi^{2} / \mathrm{d} f=3.195, \mathrm{p}<.001, \mathrm{CFI}=.908, \mathrm{RMSEA}=.087 . \mathrm{A}$ final model for statistical testing, an extension of Model $\mathrm{M}_{2}$, included the structural paths from both task values and academic buoyancy to habitual action. This model, Model $\mathrm{M}_{3}$, generated a small improvement in model fit, compared to Models $\mathrm{M}_{1}$ and $\mathrm{M}_{2}\left(\chi^{2} / \mathrm{d} f=3.186, \mathrm{p}<.001, \mathrm{CFI}=.910\right.$, RMSEA $=.085)$. These goodness-of-fit index values, we acknowledge, are relatively modest at best, and do not indicate an optimal fit $[65,66,69]$. Having said this, however, the complexity of the statistical models (e.g., 21 measured indicators, 6 latent factors), we believe, could have also accounted for the moderate model fit produced.

A summary of the goodness-of-fit index values for the three models tested is presented in Table 3. Chi-square difference tests, which we subsequently conducted, yielded evidence of acceptance for a more parsimonious model - in this case, Model $\mathrm{M}_{3}\left(\left(\Delta \chi^{2}{ }_{(\mathrm{M} 2-\mathrm{M} 3)}=7.99, p<.025\right)\right.$. The final solution for discussion, Model $\mathrm{M}_{3}$, which is illustrated in Figure 2, does support the hypothesized model. For clarity, we have omitted the non-statistical significant paths from this visual representation. All standardized structural paths are significant at the $p<.05$ and $p<.01$. Factor loadings are significant at the $p<.001$ and these ranged from .741 to $.223(M n=.791, S D=.039)$ for academic buoyancy, .595 to $.837(M n=.712, S D=.121)$ for emotional and physiological states, .759 to $.815(\mathrm{Mn}=.787$, $S D=.028)$ for task values, .400 to $.963(M n=.762 S D$ $=.248)$ for habitual action, .587 to $.927(\mathrm{Mn}=.813, S D$ $=.158$ ) for critical reflection, and .622 to .778

Table 3. Goodness-of-fit Index Values.

\begin{tabular}{|c|c|c|c|c|c|}
\hline Description & $\chi^{2}$ & $\overline{\mathrm{d} f}$ & NNFI & CFI & RMSEA \\
\hline 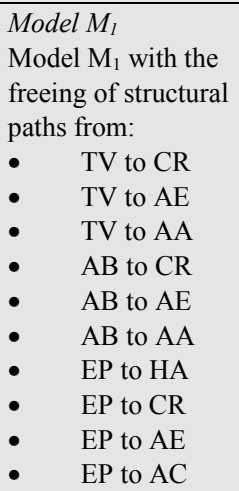 & 620.519 & 193 & .887 & .905 & .087 \\
\hline $\begin{array}{l}\text { Model } M_{2} \\
\text { Model } \mathrm{M}_{1} \text { with the } \\
\text { inclusion of the } \\
\text { following structural } \\
\text { paths from: } \\
\text { - } \quad \text { HA to AE } \\
\text { - } \mathrm{HA} \text { to AA } \\
\text { - } \quad \mathrm{CR} \text { to AE } \\
\text { - } \quad \mathrm{CR} \text { to AA }\end{array}$ & 603.834 & 189 & .888 & .908 & .087 \\
\hline $\begin{array}{l}\text { Model } M_{3} \\
\text { Model } \mathrm{M}_{2} \text { with the } \\
\text { freeing of structural } \\
\text { paths from: } \\
\text { - } \quad \mathrm{TV} \text { to HA } \\
\text { - } \quad \mathrm{AB} \text { to HA }\end{array}$ & 595.835 & 187 & .899 & .910 & .085 \\
\hline
\end{tabular}

Note: $\mathrm{AA}=$ Academic achievement, $\mathrm{AB}=$ Academic buoyancy, $\mathrm{AE}=$ Academic engagement, $\mathrm{CR}=$ Critical reflection, $\mathrm{EP}=$ Emotional and physiological states, $\mathrm{HA}=$ Habitual action, $\mathrm{CR}=$ Critical reflection. 
$(M n=.685, S D=.082)$ for academic engagement. It is interesting to note that for the hypothesized associations between the three antecedents (e.g., academic buoyancy and task values), only the association between academic buoyancy and task value is statistical significant $(\alpha=.124$, $p<.05)$.

\subsection{Direct and Indirect Effects}

In addition to Figure 2, a decomposition in direct and indirect effects is shown in Table 4. There are, in total, 13 statistical significant direct and indirect paths. For the direct effects, we note that the three antecedents were influential in their predictive effects: (i) both emotional and physiological states $(\beta=.410, p<.001)$ and academic buoyancy $(\beta=.140$, $p<.05)$ influenced habitual action, whereas task values influenced critical reflection $(\beta=.146, p<.05)$ and academic engagement $(\beta=.327, p<.001)$. Habitual action also exerted a positive effect on academic engagement $(\beta$ $=.138, p<.05)$, whereas both academic engagement $(\beta$ $=.541, p<.001)$ and critical reflection $(\beta=.186, p<.001)$ influenced academic achievement. In terms of indirect effects, in contrast, academic engagement was influenced by emotional and physiological states $(\beta=.053, p<.05)$, academic buoyancy $(\beta=.023, p<.05)$, and task values $(\beta=$ $-.024, p<.05)$, via habitual action. Habitual action also influenced academic achievement $(\beta=.075, p<.05)$, via engagement, whereas emotional and physiological states $(\beta$ $=.114, p<.025)$ and buoyancy $(\beta=-.056, p<.05)$ influenced academic achievement, via habitual action and engagement. Finally, task values influenced academic achievement $(\beta=.189, p<.001)$, via critical reflection and engagement.

\section{Discussion}

The study of quality learning in achievement settings is an important feat for accomplishment. This avenue of research inquiry is significant, especially in light of our interest to explore the cognitive-motivational nature of students' learning and its potentials for discussion and research development in the sociocultural contexts of the Asia-Pacific region. The present study is significant for its conceptualization, detailing the sequential interrelations between antecedents, cognitive processes, and adaptive outcomes. Drawing from existing theoretical tenets [e.g., social cognitive theory: 25; academic engagement: Schaufeli, et al., 2002; Suárez-Orozco, et al., 2009] and empirical evidence, we developed a framework that scoped a number of research hypotheses for statistical testing. The results obtained, in general, support the potency of academic buoyancy, emotional and physiological states, and task values as predictive antecedents of cognitive and adaptive outcomes (e.g., academic engagement). In this section of the article, we discuss the present findings with reference to potential educational practices and continuing research development.

\subsection{The Potency of Antecedents: What Do they Do}

A notable finding from the present study indicates the predictiveness of academic buoyancy (i.e., impacting on habitual action), emotional and physiological states (i.e., impacting on habitual action), and task values (i.e., impacting on critical reflection and academic engagement). Situating within the framework of social cognition [24, 25], we hypothesized that various constructs would make contributions in the prediction of cognitive processes (e.g., critical reflection) and adaptive outcomes (e.g., academic engagement). This theoretical positioning contends there are antecedents that could interact to influence students' learning and achievement-related outcomes. Previous research [e.g., 1, 8, 10] has, for example, detailed the connectedness of cognitive (e.g., deep cognitive processing) and non-cognitive (e.g., personal self-efficacy) constructs in academic learning. Academic buoyancy, as expected, influenced students' habitual action and automated learning. What is surprising, however, is the fact that buoyancy related positively with one's superficial and automated learning. Emotional and physiological states (e.g., a heightened state of anxiety), consistent with the work of Bandura (1997) and existing studies [56-58], reflect positively with one's inclination towards habitual action and automated learning. Students who express high emotional and physiological states (e.g., anxiety) would tend to exhibit more preference towards superficial learning and study habits and behaviors that reflect a sense of work-avoidant and non-serious practices.

The validation in structural relations for task values is consistent with our previous proposition, and supports existing theoretical tenets and research studies [10, 11, 16-18]. Evidence ascertained in the present study illuminates the potent effects of task values (e.g., utility value) on both critical reflection and academic engagement. The predictive contribution of task values on achievement-related outcomes, in particular, emphasizes its role as an effective antecedent. Encouraging critical reflection [e.g., "As a result of this course I have changed the way I look at myself": 28] in educational contexts may involve, in this case, the use of task values, situated within expectancy-value theories $[11,16]$. Structuring learning tasks and activities that emphasize the notion of importance and perceived usefulness may, in this instance, stimulate curiosity, subject interest, and excitement, thereby instilling a mindset towards critical reflection and academic engagement. Task values, in this case, may facilitate an approach that reflects mastery and intrinsic motivation, enabling students to think beyond the acquiring of knowledge simply for assessment purposes.

\subsection{Predictors of Academic Achievement}

The theoretical-conceptual model developed for the present study emphasizes, in particular, the interrelations between cognitive-motivational processes and adaptive outcomes in academic learning. Table 4, detailing the 
decomposition of direct and indirect effects, illustrates the central roles of both habitual action and critical reflection. Students' learning processes do not exist isolation, and previous research has shown the intricate associations between some variables (e.g., personal self-efficacy and deep cognitive process).

Academic engagement, as a distinctive construct, functions as an adaptive outcome of task values (e.g., task utility). The study of academic engagement has featured prominently in the fields of psychology and education [38, $43,70]$. This line of research inquiry, from an educational perspective, contends that quality learning and academic achievements do not necessarily predict or instill students' successes and failures. The notion of quality learning, in this analysis, espouses other achievement-related attributes, such as one's willingness to participate in his/her community and society. In this sense, from our point of view, the importance of students' overall well-being within schooling contexts may feature more prominently than the focus of academic achievement, alone. The importance of school belongingness, for example, has been acknowledged to make a major contribution in students' livelihood [70-72]. This acknowledgment, in essence, has provided a basis for us to include the construct of academic engagement in the learning process.

The inclusion of academic engagement, drawn from previous theoretical tenets and empirical findings [37, 70, 73], is supported, empirically, from our analyses, with its positive effect on achievement in educational psychology. There is a body of research that has yielded clear evidence, attesting to the strong emphasis and impact of academic engagement-disengagement. What consequences arise when students experience a sense of disengagement from schooling and society, in general? The work of Henry, et al. $[73,74]$, for example, has shown that lack of academic engagement in schooling is detrimental and results in a number of maladaptive practices and outcomes, such as school withdraw and student dropout, participation in criminal activities, etc. Proactive engagement in academia and schooling, in contrast, is positive and yields some major adaptive outcomes, such as an enhancement in learning and improvement in academic achievement. Research development into academic engagement and disengagement may, similarly, serve to benefit university teaching and learning. Active participation in university learning and related activities may feature prominently in terms of nation building, enabling students to contribute to the social and economic fabrics of society.

In the study of student learning, there is an emerging interest for researchers [e.g., 10, 75] to use positive psychology theories [e.g., personal self-efficacy: 25] to encourage and cultivate adaptive outcomes and non-avoidant practices. This educational approach is significant as it emphasizes intrinsic motives and the importance of optimistic thinking and proactive behaviors. In terms of schooling, for example, it is more logical for educators to consider students' mastery and performance based approaches to academic learning. This deliberation towards encouraging positive outcomes rather than making attempts to resolve potential detrimental consequences, from our point of view, is cost-effective and has a number of educational and social benefits. It is beneficial (e.g., promoting a heightened state of self-efficacy), in this case, for educators and researchers to invest intellectual capitals and resources into favorable outcomes for students. We need to consider, for example, pedagogical strategies, extraneous psychosocial factors, and instructional policies that could enhance students' academic engagement. Task values (e.g., utility value) within the expectancy-value theory $[11,16]$, in particular, as we note, relate positively with academic engagement and may serve as a potential informational source. A perceived sense of usefulness of a learning task for future aspirations, or the appreciation of learning for intrinsic motives would, in this sense, motivate students towards academia and learning, in general.

Table 4. Decomposition of Effects: Direct, Indirect, and Total.

\begin{tabular}{|c|c|c|c|c|c|c|c|}
\hline Predictor & Outcome & Direct & & Indirec & & Total & \\
\hline Academic buoyancy & Habitual action & .140 & * & .000 & & .140 & * \\
\hline Emotional and physiological states & & .410 & $* * *$ & .000 & & .410 & $* * *$ \\
\hline Task values & & -.099 & & .000 & & -.099 & \\
\hline Academic buoyancy & Critical reflection & -.052 & & .000 & & -.052 & \\
\hline Emotional and physiological states & & .044 & & .000 & & .044 & \\
\hline Task values & & .146 & * & .000 & & .146 & * \\
\hline Habitual action & Academic engagement & .138 & * & .000 & & .138 & * \\
\hline Critical reflection & & -.073 & & .000 & & -.073 & \\
\hline Academic buoyancy & & -.113 & & .023 & * & -.090 & \\
\hline Emotional and physiological states & & .127 & & .053 & $*$ & .180 & \\
\hline Task values & & .327 & $* * *$ & -.024 & * & .303 & $* * *$ \\
\hline Academic engagement & Achievement & .541 & $* * *$ & .000 & & .541 & $* * *$ \\
\hline Habitual action & & .021 & & .075 & $*$ & .096 & \\
\hline Critical reflection & & .186 & $* * *$ & -.039 & & .147 & $* * *$ \\
\hline Academic buoyancy & & .102 & & -.056 & $*$ & .046 & \\
\hline Emotional and physiological states & & -.111 & & .114 & $* *$ & .003 & \\
\hline Task values & & -.031 & & .189 & $* * *$ & .158 & \\
\hline
\end{tabular}

Note: $* * p<.01, * * * p<.001$. 
We note that critical reflection also exerted a positive effect on academic achievement (e.g., critical reflection $\rightarrow$ achievement, $\beta=.186, p<.001)$. The established association between critical reflection and academic achievement is consistent with findings obtained previously [13, 33], and highlights the predictive and explanatory power of critical reflection. This finding pertaining to the central role of critical reflection entails a number of implications for applied educational practices. Critical reflection, in this analysis, may impart and/or associate with achievement-related attributes (e.g., deep cognitive processing) that could, in turn, result in the enhancement of academic learning $[13,76]$. This cognitive process construct, of course, reflects a high-order level of reflection $[13,28$, 77], requiring personal experience, effort, and motivation. Some students in classroom situations may embrace in superficial thinking and habitual practices [e.g., "If I follow what the lecturer says, I do not have to think too much on this course": 28], given their limited knowledge and experiences, lack of confidence, and/or motivation.

The positive effect of critical reflection [13, 28, 76] indicates that there is an important need for educators to consider. A heightened sense of critical reflection enables students to achieve and excel, academically. Strategies to encourage and foster this practice of critical reflection may include, in this case, the use of task values and other motivational means [e.g., instilling personal self-efficacy: 25]. Subject contents and learning activities that stimulate intellectual curiosity and interest may, in this analysis, instill authenticity, meaning, and purpose to learning (e.g., Why am I doing this subject and what implications does it have for me in terms of my future aspirations?).

\section{Conclusion}

The correlational investigation detailed in this article has contributed, overall, to the study of students' learning in achievement contexts. Evidence ascertained from causal modeling procedures supports the theoretical-conceptual model and research hypotheses relating to the intricate associations between cognitive, motivational, and adaptive outcomes. Empirically, in terms of advancement and continuing research development, we have established some notable trajectories that scoped the effects of three psychological antecedents on cognitive processes and adaptive outcomes. We encourage researchers to explore the mentioned avenue of inquiry and its respective findings with other educational levels and/or cultural samples.

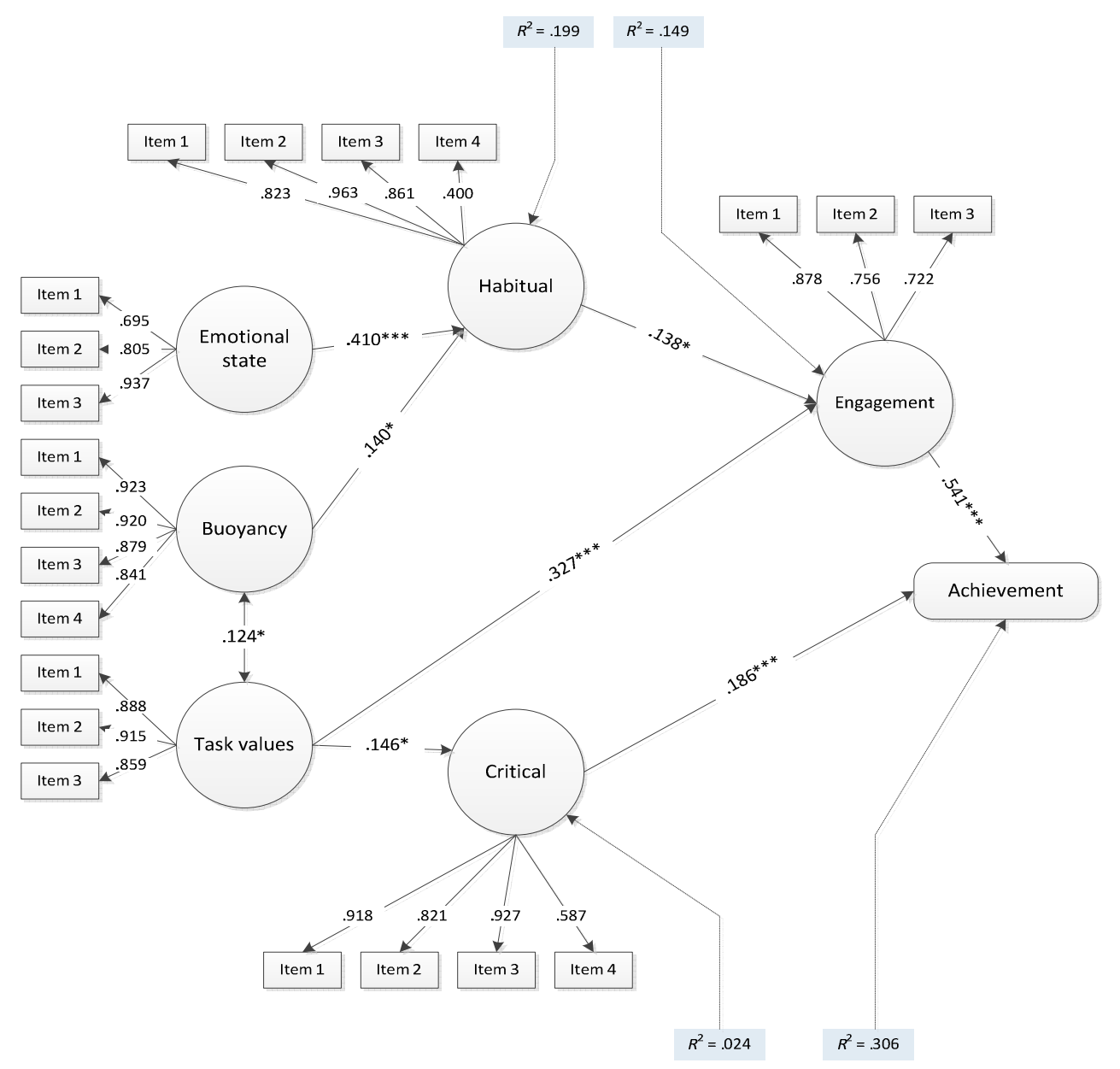

Figure 2. A Final Solution for Cognitive-Motivational Processes of Learning. 
We note some major limitations that arise from the present study, which in our view require consideration and further research development. First, the sample used in this investigation was purposive and does not provide a basis for comparison and/or generalizability. We are mindful that the participants here were enrolled in Teacher Education courses and studied the subject, educational psychology. By all means, we acknowledge that the findings produced are situated within the learning context of educational psychology only. Proactive engagement in educational psychology, alone, does not necessarily transfer to other subject domains. This restricted sample and subject domain, hence, warrants cautious interpretation and inference, regarding the interrelations between the variables tested. The majority of Teacher Education courses, in this analysis, include humanity and social science subjects, differing to a large extent from other degree programs (e.g., Sciences). The nature of a subject matter (e.g., pure mathematics versus computing science)[78, 79], similarly, instills different epistemological beliefs, patterns in cognition and motivation, etc. Hard pure theoretical subjects and/or units such as Calculus may not necessarily elicit interest or curiosity, and may consequently disengage some students, especially those who are not well-versed in the area of mathematics. On this basis, we recommend researchers replicate our findings to other cultural samples and in different subject areas.

Second, we acknowledge that the use of a cross-sectional design deterred us from making statistical inference about causality and causal predominance between the variables $[80,81]$. Throughout this article, we made reference to the term 'effects', consequently as a result of SEM procedures that enabled the decomposition of direct, indirect, and total effects [66, 68, 69]. We caution this usage and interpretation and suggest, alternatively, for the use of longitudinal data, analyzed within the framework of SEM. In the absence of experimental manipulation, it would be more appropriate to use multi-wave panel designs in the study of cognitive and motivational processes [6, 80, 82]. One emphasis, in particular, entails an exploration in temporally displaced effects of cognitive and motivational variables. There has been some recent research [18, 83-85], which utilized this methodological approach to study the effects of cognitive and motivational variables on future achievement-related outcomes (e.g., career choice). How lasting, for example, is the effect of academic buoyancy on students' performance outcomes in a subject matter?

The goodness-of-fit index values of our solutions are modest at best, and do not necessarily reflect the optimal standard (e.g., CFI > .95) for finalization and acceptance. Modification fit index values are readily available, provided by statistical software packages (e.g., LISREL) used to analyze correlational data. Having said this, however, we note previous recommendations [69] that respecifications of a priori models are often based on strong theoretical reasoning and/or empirical evidence. We believe that, in this instance, the original conceptualization depicted in Figure 1 is logically sound. There is limited, if any, reasoning to support potential a posteriori analyzes of the data. On this basis, given the less-than-optimal values of the fit of Model $\mathrm{M}_{3}$, we recommend the replication and statistical testing our final model to other cross-cultural samples. Successful structural validation would, in this sense, support the cross-cultural generalizability of the theoretical-conceptual model outlined in this study. We are cognizant that the sample used in this investigation was average in size, and in part, the sampling, not representative in nature, did not discern possible gender differences in the variables under investigation. It would also be of theoretical interest, in a similar vein, for researchers to consider other academic domains of functioning in the study of academic engagement and quality learning.

One aspect for consideration is the tracing of structural relations (e.g., academic buoyancy and intrinsic motivation), using longitudinal methodological designs [6, 80, 86, 87]. Data collected on multiple occasions, analyzed within the framework of latent growth modeling (LGM) procedures [88-90] are more advantageous and may allow us to test and identify developmental courses of psychological variables. Furthermore, the inclusion of extraneous factors from the home and institution surroundings (e.g., parental involvement) may explain and account for the initial states and overall variance in changes of cognitive and motivational processes of learning.

\section{References}

[1] Martin, A.J. and H.W. Marsh, Academic buoyancy: Towards an understanding of students' everyday academic resilience. Journal of School Psychology, 2008. 46(1): p. 53-83.

[2] Martin, A.J. and H.W. Marsh, Workplace and academic buoyancy: Psychometric assessment and construct validity amongst school personnel and students. Journal of Psychoeducational Assessment, 2008. 26(2): p. 168 - 184.

[3] Pintrich, P.R., et al., A manual for the use of the Motivated Strategies for Learning Questionnaire (MSLQ). 1991, Ann Arbor, MI: National Centre for Research to Improve Postsecondary Teaching and Learning.

[4] Fenollar, P., S. Román, and P.J. Cuestas, University students' academic performance: An integrative conceptual framework and empirical analysis. British Journal of Educational Psychology, 2007. 77(Pt 4): p. 873-891.

[5] Lau, S., A.D. Liem, and Y. Nie, Task - and self-related pathways to deep learning: The mediating role of achievement goals, classroom attentiveness, and group participation. British Journal of Educational Psychology, 2008. 78(4): p. 639-662.

[6] Martin, A.J., et al., Longitudinal modelling of academic buoyancy and motivation: Do the 5Cs hold up over time? British Journal of Educational Psychology, 2010. 80(3): p. 473-496. 
[7] Phan, H.P., Students' academic performance and various cognitive processes of learning: An integrative framework and empirical analysis. Educational Psychology, 2010. 30(3): p. $297-322$.

[8] Diseth, A., Self-efficacy, goal orientations and learning strategies as mediators between preceding and subsequent academic achievement. Learning and Individual Differences, 2011. 21(2): p. 191-195.

[9] Author, Title: I (Interplay between......). 2013.

[10] Liem, A.D., S. Lau, and Y. Nie, The role of self-efficacy, task value, and achievement goals in predicting learning strategies, task disengagement, peer relationship, and achievement outcome. Contemporary Educational Psychology, 2008. 33(4): p. 486-512.

[11] Eccles, J.S., et al., Expectancies, values and academic behaviors, in Achievement and achievement motives, J.T. Spence, Editor. 1983, W. H. Freemen: San Francisco. p. $75-146$.

[12] Simons, J., S. Dewitte, and W. Lens, The role of different types of instrumentality in motivation, study strategies, and performance: Know why you learn, so you'll know what you learn! British Journal of Educational Psychology, 2004. 74(Pt 3): p. 343-360.

[13] Leung, D.Y.P. and D. Kember, The relationship between approaches to learning and reflection upon practice. Educational Psychology, 2003. 23(1): p. 61-71.

[14] Martin, A.J. and H.W. Marsh, Academic resilience and academic buoyancy: Multidimensional and hierarchical conceptual framing of causes, correlates and cognate constructs. Oxford Review of Education, 2009. 35(3): p. 353 -370 .

[15] Martin, A.J. and H.W. Marsh, Academic resilience and its psychological and educational correlates: A construct validity approach. Psychology in the Schools, 2006. 43(3): $\mathrm{p}$ 267-281.

[16] Wigfield, A. and J.S. Eccles, Expectancy-value theory of achievement motivation. Contemporary Educational Psychology, 2000. 25(1): p. 68-81.

[17] Hulleman, C.S., et al., Task values, achievement goals, and interest: An integrative analysis. Journal of Educational Psychology, 2008. 100(2): p. 398-416.

[18] Harackiewicz, J.M., et al., The role of achievement goals in the development of interest: Reciprocal relations between achievement goals, interest and performance. Journal of Educational Psychology, 2008. 100: p. 105 - 122.

[19] Meece, J.L., A. Wigfield, and J.S. Eccles, Predictors of math anxiety and its influence on young adolescents' course enrollment intentions and performance in mathematics. Journal of Educational Psychology, 1990. 82: p. 60 - 70.

[20] Updegraff, K.A., et al., Course enrollment as self-regulatory behavior: Who takes optimal high school math courses? Learning and Individual Differences, 1996. 8: p. 239 - 259.

[21] Greene, B.A., et al., Predicting high school students' cognitive engagement and achievement: Contributions of classroom perceptions and motivation. Contemporary Educational Psychology, 2004. 29: p. 462 - 482.
[22] Cole, J.S., D.A. Bergin, and T.A. Whittaker, Predicting student achievement for low stakes tests with effort and task value. Contemporary Educational Psychology, 2008. 33: p. 609-624.

[23] Pintrich, P.R., et al., Reliability and predictive validity of the motivated strategies for learning questionnaire (MSLQ). Educational and Psychological Measurement, 1993. 53: p. 810-814.

[24] Bandura, A., Social foundations of thought and action: A social cognitive theory. 1986, Englewood Cliffs, NJ: Prentice-Hall.

[25] Bandura, A., Self-efficacy: The exercise of control. 1997, New York: W. H. Freeman \& Co.

[26] Pajares, F. and J. Kranzler, Self-efficacy beliefs and general mental ability in mathematical problem solving. Contemporary Educational Psychology, 1995. 20: p. 426-443.

[27] Pajares, F. and M.J. Johnson, Self-efficacy beliefs and the writing performance of entering high school students. Psychology in the Schools, 1996. 33: p. 163-175.

[28] Kember, D., et al., Development of a questionnaire to measure the level of reflective thinking. Assessment \& Evaluation in Higher Education, 2000. 25(4): p. 381-389.

[29] Dewey, J., How we think: A restatement of the relation of reflective thinking to the educative process. 1933, Boston: D. C Health (Original work published in 1909).

[30] Schön, D., The reflective practitioner: How professionals think in action. 1983, New York: Basic Books.

[31] Schön, D., Educating the reflective practitioner. 1987, San Francisco, CA: Jossey-Bass.

[32] Phan, H.P., An examination of reflective thinking, learning approaches, and self-efficacy beliefs at the University of the South Pacific: A path analysis. Educational Psychology, 2007. 27(6): p. 789-806.

[33] Phan, H.P., Exploring students' reflective thinking practice, deep processing strategies, effort, and achievement goal orientations. Educational Psychology, 2009. 29(3): p. 297-313.

[34] Pike, G.R. and G.D. Kuh, First - and second-generation college students: A comparison of their engagement and intellectual development. The Journal of Higher Education, 2005. 76(3): p. $276-300$.

[35] Carini, R.M., G.D. Kuh, and S.P. Klein, Student engagement and student learning: Testing the linkages. Research in Higher Education, 2006. 47(1): p. 1 - 32.

[36] Lester, J., J.B. Leonard, and D. Mathias, Transfer student engagement: Blurring of social and academic engagement. Community College Review, 2013. 41(3): p. 202 - 222.

[37] Salamonson, Y., S. Andrew, and B. Everett, Academic engagement and disengagement as predictors of performance in pathphysiology among nursing students. Contemporary Nurse, 2009. 32(1 - 2): p. 123 - 132.

[38] Suárez-Orozco, C., A. Pimentel, and M. Martin, The significance of relationships: Academic engagement and achievement among newcomer immigrant youth. Teachers College Record, 2009. 111(3): p. 712 - 749. 
[39] Axelson, R.D. and A. Flick, Defining student engagement. Change: The Magazine of Higher Education, 2010. 43(1): p. $38-43$.

[40] Steinberg, S., B.B. Brown, and S.M. Dornbusch, Beyond the classroom. 1996, New York, NY: Simon and Schuster.

[41] Greenwood, C.R., B.T. Horton, and C.A. Utley, Academic engagement: Current perspectives in research and practice. School Psychology Review, 2002. 31(3): p. 1 - 31.

[42] Marks, H.M., Student engagement in instructional activity: Patterns in the elementary, miiddle, and high school years. America Educational Research Journal, 2000. 37: p. 153 184.

[43] Fredricks, J.A., P.C. Blumenfeld, and A.H. Paris, School engagement: Potential of the concept, state of the evidence. Review of Educational Research, 2004. 74(1): p. 59-109.

[44] Pace, C.R., Measuring the quality of student effort. Current Issues in Higher Education, 1980. 2: p. 10 - 16.

[45] Austin, A.W., Student involvement: A developmental theory for higher education. Journal of College Student Development, 1984. 25(4): p. 297 - 308.

[46] Tinto, V., Rethinking the causes and cures of student attrition. 1987, Chicago: University of Chicago Press.

[47] Tinto, V., Leaving college: Rethinking the causes and cures of student attrition. 2nd ed. 1993, Chicago: University of Chicago Press.

[48] Chickering, A.W. and Z.F. Gamson, Seven principles for good practice in undergraduate education. AAHE Bulletin, 1987. March: p. 3 - 7.

[49] Kuh, G.D. and Others, Student success in college: Creating conditions that matter. 2005, San Francisco: Jossey-Bass.

[50] Kuh, G.D., et al., Involving colleges: Successful approaches to fostering student learning and personal development outisde the classroom. 1991, San Francisco: Jossey-Bass.

[51] Kuh, G.D., The National Surveys of Student Engagement: Conceptual and empirical foundations. New Directions for Institutional Research, 2009. 141: p. 5 - 20.

[52] Kuh, G.D., Assessing what really matters to student learning: Inside the National Survey of Student Engagement. Change, 2001. 33(3): p. 10 - 17, 66.

[53] Kuh, G.D., What we're learning about student engagement from NSSE. Change, 2003. 35(2): p. 24 - 32.

[54] Kuh, G.D., The National Survey of Student Engagement: Conceptual framework and overview of psychometric properties, in Framework and Psychometric Properties. 2003, Indiana University Center for Postsecondary Research and Planning. p. 1 - 26.

[55] Schaufeli, W.B., et al., The measurement of engagement and burnout: A two sample confirmatory factor analytic approach. Journal of Happiness Studies, 2002. 3: p. 71 - 92.

[56] Pajares, F. and G. Valiante, Influence of self-efficacy on elementary students' writing. The Journal of Educational Research, 1997. 90: p. 353-360.

[57] Pajares, F., Self-Efficacy beliefs and mathematical problem-solving of gifted students. Contemporary
Educational Psychology, 1996. 21: p. 325-344.

[58] Pajares, F., M.D. Miller, and M.J. Johnson, Gender differences in writing self-efficacy beliefs of elementary school students. Journal of Educational Psychology, 1999. 91(1): p. 50-61.

[59] Martin, A.J. and H. Marsh, Motivating boys and motivating girls: Does teacher gender really make a difference? Australian Journal of Education, 2005. 49(3): p. 320 - 334.

[60] Martin, A.J., The Student Motivation Scale: A tool for measuring and enhancing motivation. Australian Journal of Guidance and Counselling, 2001. 11: p. 1 - 20.

[61] Author, Title B: (An integrated.....). 2014.

[62] Lent, R.W., F.G. Lopez, and K.J. Bieschke, Mathematics self-efficacy: Sources and relation to science-based career choice. Journal of Counseling Psychology, 1991. 38(4): p. 424-430.

[63] Matsui, T., K. Matsui, and R. Ohnishi, Mechanisms underlying math self-efficacy learning of college students. Journal of Vocational Behavior, 1990. 37: p. 225-238.

[64] Byrne, B.M., Structural equation modeling with AMOS: Basic concepts, applications, and programming. 2nd ed. 2010, New York, NY: Routledge.

[65] Kline, R.B., Principles and practice of structural equation modeling 3rd ed. 2011, New York, NY: The Guilford Press.

[66] Loehlin, J.C., Latent variable models: An introduction to factor, path, and structural equation analysis. 4th ed. 2004, Mahwah, NJ: Lawrence Erlbaum Associates, Publishers.

[67] Schumacker, R.E. and R.G. Lomax, A beginner's guide to structural equation modeling. 2nd ed. 2004, Mahwah, NJ: Lawrence Erlbaum Associates, Inc.

[68] Chou, C.P. and P.M. Bentler, Estimates and tests in structural equation modelling, in Structural equation modelling: Concepts, issues, and applications, R.H. Hoyle, Editor. 1995, Sage: Thousand Oaks, CA. p. 37-55.

[69] Byrne, B.M., Structural equation modelling with LISREL, PRELIS, and SIMPLIS. 1998, Mahwah, NJ: Erlbaum.

[70] Willms, J.D., Student engagement at school: A sense of belonging and participation. Results from PISA 2000. 2003, Organisation for Economic Co-operation and Development (OECD).

[71] Osterman, K.F., Students' need for belonging in the school community. Review of Educational Research, 2000. 70: p. $323-367$

[72] Ma, X., Sense of belonging to school: Can schools make a difference? Journal of Educational Research, 2003. 96(6): p. $1-9$.

[73] Henry, K.L., K.E. Knight, and T.P. Thornberry, School disengagement as a predictor of dropout, delinquency, and problem substance use during adolescence and early adulthood. Journal of Youth Adolescence, 2012. 41: p. 156 166.

[74] Henry, K.L., Academic achievement and adolescent drug use: An examination of reciprocal effects and correlated growth trajectories. Journal of School Health, 2010. 80(1): p. $38-43$. 
[75] Yeung, A.S., Student self-concept and effort: Gender and grade differences. Educational Psychology, 2011. 31: p. 749 -772 .

[76] Author, Title: B (Critical thinking as.....). 2010.

[77] Yanchar, S.C., B.D. Slife, and R. Warne, Critical thinking as disciplinary practice. Review of General Psychology, 2008. 12(3): p. 265-281.

[78] Becher, T., The disciplinary shaping of the professions, in The academic profession, B.R. Clarke, Editor. 1987, University of California Press: Berkley, CA. p. 271 - 303.

[79] Becher, T., Academic tribes and territories 1989, Milton Keynes, UK: Open University Press.

[80] Marsh, H.W. and A.S. Yeung, Causal effects of academic self-concept on academic achievement: Structural equation models of longitudinal data. Journal of Educational Psychology, 1997. 89(1): p. 41-54.

[81] Marsh, H.W. and A.S. Yeung, Longitudinal structural equation models of academic self-concept and achievement: Gender differences in the development of math and English constructs. American Educational Research Journal, 1998. 35(4): p. 705-738.

[82] Phan, H.P., Cognitive processes in university learning: A developmental framework using structural equation modelling. British Journal of Educational Psychology, 2011. 81(3): p. 509-530.

[83] Bong, M., Role of self-efficacy and task-value in predicting college students' course performance and future enrollment intentions. Contemporary Educational Psychology, 2001. 26: p. $553-570$.
[84] Phan, H.P., Informational sources, self-efficacy, and achievement: A temporally displaced approach. Educational Psychology, 2012. 32(6): p. 699 - 726.

[85] Durik, A.M., C.M. Lovejoy, and S.J. Johnson, A longitudinal study of achievement goals for college in general: Predicting cumulative GPA and diversity in course selection. Contemporary Educational Psychology, 2009. 34: p. 113-119.

[86] Rogosa, D., Causal models in longitudinal research: Rationale, formulation, and interpretation, in Longitudinal research in the study of behaviour and development, J.R. Nesselroade and P.B. Balles, Editors. 1979, Academic Press: New York. p. 263-302.

[87] Phan, H.P., Deep Processing Strategies and Critical Thinking: Developmental Trajectories Using Latent Growth Analyses. The Journal of Educational Research, 2011. 104(4): p. 283-294.

[88] McArdle, J.J. and J.R. Nesselroade, Growth curve analysis in contemporary psychological research, in Handbook of psychology: Research methods in psychology, J.A. Schinka and W.F. Velicer, Editors. 2003, Wiley: New York. p. 447-480.

[89] Bollen, K.A. and P.J. Curran, Latent curve models: A structural equation perspective. Wiley series in probability and statistics, ed. W.A. Shewhart and S.S. Wilks. 2006, Hoboken, NJ: Wiley.

[90] Hancock, G.R. and F.R. Lawrence, Using latent growth models to evaluate longitudinal change, in Structural equation modeling: A second course, G.R. Hancock and R.O. Mueller, Editors. 2006, Information Age Publishing: Greenwich, Connecticut. p. 171-196. 